\title{
Radiographic study of peak velocity of pelvic incidence in adolescent idiopathic scoliosis
}

\author{
Yuancheng Zhang ${ }^{1,2 \#}$, Shibin Shu ${ }^{1 \#}$, Qi Gu ${ }^{1}$, Filippo Mandelli ${ }^{2}$, Tianyuan Zhang ${ }^{1}$, Wenting Jing ${ }^{1}$, Yong Qiu ${ }^{1}$, \\ Zezhang Zhu' ${ }^{1}$, Hongda Bao ${ }^{1}$ \\ ${ }^{1}$ Department of Spine Surgery, Drum Tower Hospital, Nanjing University Medical School, Nanjing, China; ${ }^{2}$ Department of Spine Surgery, \\ University Hospital Basel, Basel, Switzerland
}

Contributions: (I) Conception and design: Y Zhang, H Bao; (II) Administrative support: Z Zhu, Y Qiu; (III) Provision of study materials or patients: Z Zhu, Y Qiu; (IV) Collection and assembly of data: Y Zhang, S Shu, T Zhang; (V) Data analysis and interpretation: S Shu, Q Gu, W Jing; (VI) Manuscript writing: All authors; (VII) Final approval of manuscript: All authors.

"These authors contributed equally to this work.

Correspondence to: Hongda Bao, MD. Department of Spine Surgery, Drum Tower Hospital, Nanjing University Medical School, Nanjing 210008, China. Email: baohongda123@gmail.com.

Background: Pelvic incidence (PI), a parameter related to the ideal spinopelvic alignment, is a morphological parameter that is usually considered fixed, but the PI's growth during adolescence has been reported. We investigated the peak PI velocity during adolescence and describe the relationship between increasing PI and changes in the morphology of the pelvis and sacrum.

Methods: We measured standing height $(\mathrm{SH})$ and radiological anatomical parameters including pelvic height $(\mathrm{PH})$, pelvic width (PW), sacral width (SW), femoral head-sacrum (FH-S), sacrum-coccyx (S-C) length, and S-C distance at each follow-up of 76 adolescent idiopathic scoliosis (AIS) patients. $\Delta$ Parameter was the difference between the next measurement and the previous one. Growth velocity was $\Delta$ Parameter divided by time interval. All $\triangle$ Parameters were compared between different Risser stages using repeatedmeasures analysis of variance (ANOVA). The Pearson coefficients of correlation were calculated to assess the relationships between PI and $\triangle$ Parameters.

Results: PI reached peak growth with a $1.6 \%$ year growth in females and $1.8 \%$ year in males at Risser stage 1 . PI tended to grow rapidly with Risser 0 and closed triradiate cartilage (female: $1.3 \%$ year and male: $1.4 \%$ year) and to slow down at Risser 2 (female: $1.2 \%$ year and male: $1.3 \%$ year). $\Delta \mathrm{PI}$ strongly correlated with $\Delta \mathrm{FH}-\mathrm{S}$ $(\mathrm{R}>0.508, \mathrm{P}<0.05)$ and also correlated with $\Delta \mathrm{SH}, \Delta \mathrm{PH}, \Delta \mathrm{PW}, \Delta \mathrm{SW}$, and $\Delta \mathrm{S}-\mathrm{C}$ length $(\mathrm{R}>0.192, \mathrm{P}<0.05)$ but not correlated with $\Delta \mathrm{S}-\mathrm{C}$ distance and $\Delta \mathrm{S}-\mathrm{C}$ ratio.

Conclusions: In patients with AIS, the peak PI velocity is at Risser 1, and it is still increasing at Risser 5. Our result suggested that the growth of the PI may be associated with $\mathrm{SH}$ and changing pelvic morphology during skeletal growth of adolescence.

Keywords: Adolescent idiopathic scoliosis (AIS); peak height velocity (PHV); pelvic incidence (PI); sagittal alignment

Submitted Apr 09, 2021. Accepted for publication Sep 03, 2021.

doi: 10.21037/qims-21-391

View this article at: https://dx.doi.org/10.21037/qims-21-391 


\section{Introduction}

The importance of the sagittal alignment of the pelvis has been well recognized in recent decades. In 1994 Dubousset proposed the concept of the pelvic vertebra, suggesting the pelvis be considered as just another caudal vertebra (1). In their studies, Duval-Beaupère et al. (2) introduced the concept of "pelvic incidence" (PI) and described two positional parameters, the pelvic tilt (PT) and the sacral slope (SS). Among the pelvic parameters, PI is considered as the most important, because it is a morphological parameter and defines the ideal sacral orientation, with direct effects on the ideal lumbar lordosis. PI is also an important factor in determining the sagittal balance and a higher PI is considered to be one of the causative factors in the development and progression of spondylolisthesis and is used as one of the parameters to check when evaluating and treating spondylolisthesis $(3,4)$. Some studies also reported that higher PI was also a risk for proximal junctional kyphosis (PJK) after surgical treatment of adult scoliosis $(5,6)$. Lower magnitude of PI was also found associated with intervertebral disc dehydration in young adults (7).

$\mathrm{PI}$ is an anatomical parameter of the pelvis that is subject to changes during skeletal maturation and the development of the pelvic morphology before stabilizing in adulthood $(8-11)$. It is believed to be stable in the adult population, but there is evidence of some changes in older people due to the degenerative process at the sacroiliac joints $(12,13)$. There is a lack of research on the specific pattern of PI changes during adolescence, and knowledge of PI changes can help guide the treatment of adolescent idiopathic scoliosis (AIS) patients, assess their overall skeletal growth, and predict the risk of postoperative PJK.

A previous study reported that PI was associated with sacral curvature, sacroiliac joint angulation, and sacral ala width, but that study was conducted using anatomical specimens, and thus the dynamic relationship between anatomical morphology and PI during adolescence remains unknown (14).

The purpose of this longitudinal study was to investigate the velocity of PI-growth during adolescence, defining the peak PI velocity as the peak velocity of the increasing PI. Furthermore, we aimed to describe the relationship between increasing PI and changes in the morphology of the pelvis and sacrum.

\section{Methods}

\section{Coborts}

The study was conducted in accordance with the
Declaration of Helsinki (as revised in 2013). This retrospective radiographic study was approved by the Institutional Review Board of the Affiliated Drum Tower Hospital of Nanjing University Medical School (No. 2017053), and informed consent was given by each subject. All subjects who received brace treatment at the hospital clinic between January 2007 and December 2017 were included. The inclusion criteria were (I) AIS patients undergoing standardized thoraco-lumbo-sacral orthosis brace treatment, (II) continuous follow-up through Risser stages $0-5$, have at least one follow-up in each Risser stage, have two follow-ups in Risser 0 including closed and opened triradiate cartilage, and (III) full spinal images with clear visibility of the sacroiliac joint in the coronal plane, and of the femoral heads and sacrum in the sagittal plane at each follow-up (all patients removed the brace $24 \mathrm{~h}$ before $\mathrm{X}$-rays). The exclusion criteria were (I) previous spinal surgery, (II) any sign of growth abnormalities, (III) skeletal dysplasia or dwarfism, (IV) asymmetry or unclear Risser stage on $\mathrm{X}$-rays, and $(\mathrm{V})$ presence of any hip disease.

\section{Measurements}

Full spine radiographs were taken, and standing height (SH) was measured at the initial visit and at each followup. Skeletal maturity was defined according to the Risser stage. Our study defined Risser 0 with the opened triradiate cartilage as Risser 0, Risser 0 with the closed triradiate cartilage as Risser 0.5. According to a previous study showing peak height velocity (PHV) at Risser 0 with closed triradiate cartilage (15), we considered Risser 0.5 stage as the presumed PHV.

The radiological measurements included PI, pelvic height $(\mathrm{PH})$, pelvic width $(\mathrm{PW})$, sacral width $(\mathrm{SW})$, femoral head-sacrum (FH-S), sacrum-coccyx (S-C) length, S-C distance and sacral curvature ratio (Figure 1). PI was defined as the angle between the perpendicular to the sacral plate at its midpoint and the line connecting this point to the middle axis of the femoral heads, the center of the overlapped femoral heads being taken as the midpoint (2). According to Bao et al. (16), we used $\mathrm{PH}$ and $\mathrm{PW}$ to represent the radiographic anatomical morphology of the pelvis. $\mathrm{PH}$ was defined as the distance between a horizontal line passing through the upper margin of the ilium and another through the ischial tuberosity. PW was defined as the distance between two vertical lines passing through the flank margin of the ilium. We defined FH-S as the distance between the center of the bicoxo-femoral axis and a vertical line through 


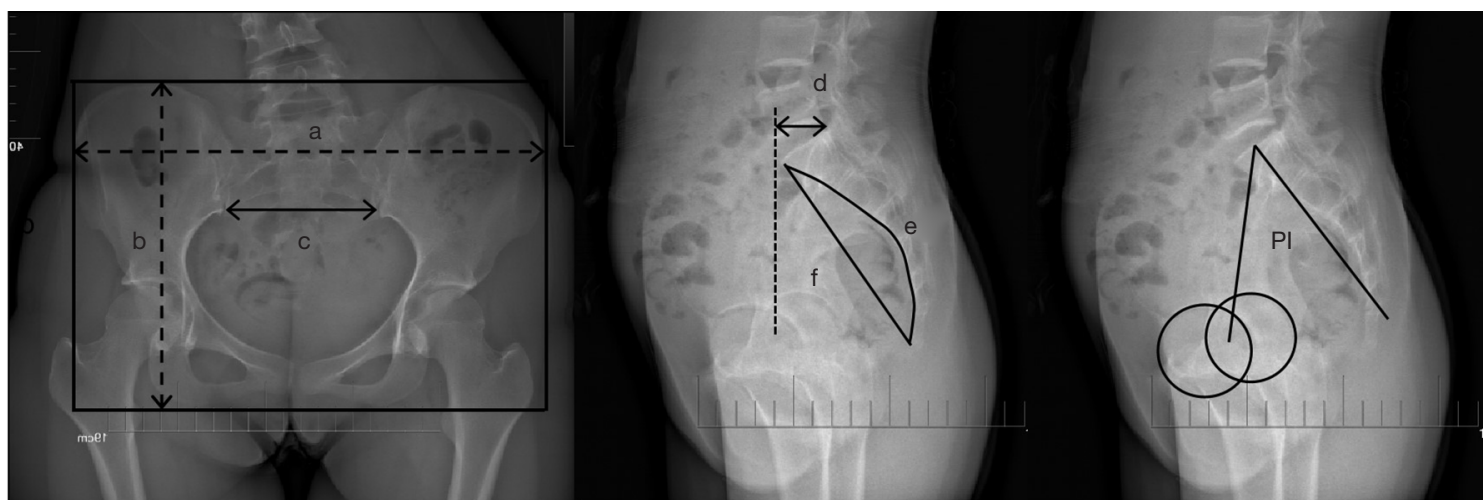

Figure 1 Measurement of parameters. a: PW; b: PH; c: SW; d: FH-S; e: S-C length; f: S-C distance. S-C length was measured on Image software (version 1.43u, Wayne Rasband, NIH, USA). PW, pelvic width; PH, pelvic height; SW, sacral width; FH-S, femoral head-sacrum; S-C, sacrum-coccyx; PI, pelvic incidence.

the posterior superior corner of the S1, which shows the thickness of the pelvis. According to Abola et al. (14), we defined SW, S-C length, S-C distance, and sacral curvature ratio to represent the radiographic anatomical morphology. SW was defined as the distance between the most caudal visible portion of the sacroiliac joints in the coronal plane. S-C length was defined as the curve length of the anterior border of the sacrum in the sagittal plane. S-C distance was defined as the distance between the anterior superior corner of the sacrum and the most caudal point of the coccyx in the sagittal plane.

The sacral curvature ratio was defined as the ratio of S-C length and S-C distance (Figure 1). $\Delta$ Parameters were defined as Parameters at the next follow-up minus Parameters at the previous follow-up. Growth velocity was defined as $\Delta$ Parameters divided by the time interval. The measurements were performed on digital images stored in the Surgimap ${ }^{\circledR}$ software (Nemaris Inc., New York, NY, USA). The S-C length was measured on ImageJ software (Version 1.43u, Wayne Rasband, NIH, USA). All radiographic measurements were independently performed by a spine surgeon (HB) and a resident (YZ) of the Department of Spine Surgery, Drum Tower Hospital. The measurements were performed twice with a 2 -week interval by YZ (3 years' experience in radiological measurement) and the average was used for further analysis.

\section{Statistical analysis}

Data were statistically analyzed with SPSS Statistics v 20.0 (IBM Corp, Armonk, NY, USA). Measured values are expressed as mean and standard deviation (SD). Descriptive statistics were performed to analyze the patients' demographics. All $\Delta$ Parameters were compared between different Risser stages using repeated-measures analysis of variance (ANOVA) with Bonferroni post hoc comparisons. For the intra- and interobserver reliability analyses, the intraclass correlation coefficient (ICC) was calculated. The Pearson coefficients of correlation were calculated to assess the relationships between $\Delta \mathrm{PI}$ and $\Delta$ Parameters. Strength of correlation were categorized as weak $(0.10<\mathrm{R}<0.30)$, moderate $(0.30<\mathrm{R}<0.50)$ or strong $(0.50<\mathrm{R}<1.00)$. $\mathrm{P}<0.05$ was regarded as a statistically significant difference.

\section{Results}

A total of 76 AIS patients (17 male, 59 female) were included in our study. The mean age of the female and male patients at the first visit was 10.0 years and 11.5 years, respectively. The mean Cobb angle of all the patients at the first visit was $27.8^{\circ}$.

The intra- and interobserver reliability were excellent for all the parameters (ICC $>0.952 ;$ Table 1). Figure 2 shows the changes in PI and SH. Tables 2,3 show the growth velocity of PI and the pelvis morphology in females and males, respectively. The peak PI velocity occurred during Risser stage 1 ( $1.6^{\circ}$ year for females, $1.8^{\circ}$ year for males). The PI also increased rapidly in Risser $0.5(1.3 \%$ year for females, $1.4 \%$ year for males), followed by Risser $2(1.2 \%$ year for females, $1.3 \%$ year for males). The growth velocity of the PI showed a decrease in Risser $3(0.6 \%$ year for females, $0.9 \%$ year for males). A slower change in the PI was found during Risser 4 ( $0.5 \%$ year for females, $0.8 \%$ year for males). Although the increase in the PI was declining, it is still 
Table 1 ICC for intra- and inter-observer repeatability of parameters

\begin{tabular}{lll}
\hline & Intra-observer ICC & Inter-observer ICC \\
\hline PI & $0.975(0.962-0.984)$ & $0.968(0.957-0.978)$ \\
PH & $0.987(0.981-0.992)$ & $0.971(0.960-0.983)$ \\
PW & $0.983(0.977-0.989)$ & $0.977(0.971-0.986)$ \\
SW & $0.993(0.988-0.997)$ & $0.963(0.948-0.979)$ \\
FH-S & $0.987(0.981-0.992)$ & $0.969(0.952-0.975)$ \\
S-C length & $0.974(0.961-0.985)$ & $0.952(0.934-0.968)$ \\
S-C distance & $0.983(0.971-0.989)$ & $0.961(0.943-0.976)$ \\
\hline
\end{tabular}

Values are given as the reliability with $95 \%$ confidence intervals in parentheses. ICC, intraclass correlation coefficients; PI, pelvic incidence; PH, pelvic height; PW, pelvic width; SW, sacral width; FH-S, femoral head-sacrum; S-C, sacrum-coccyx.
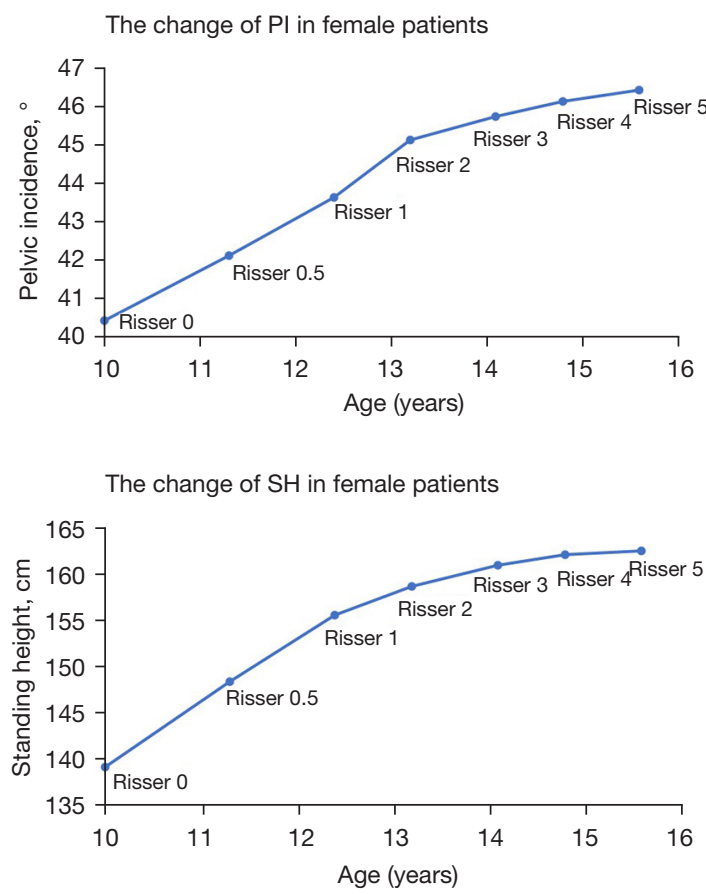
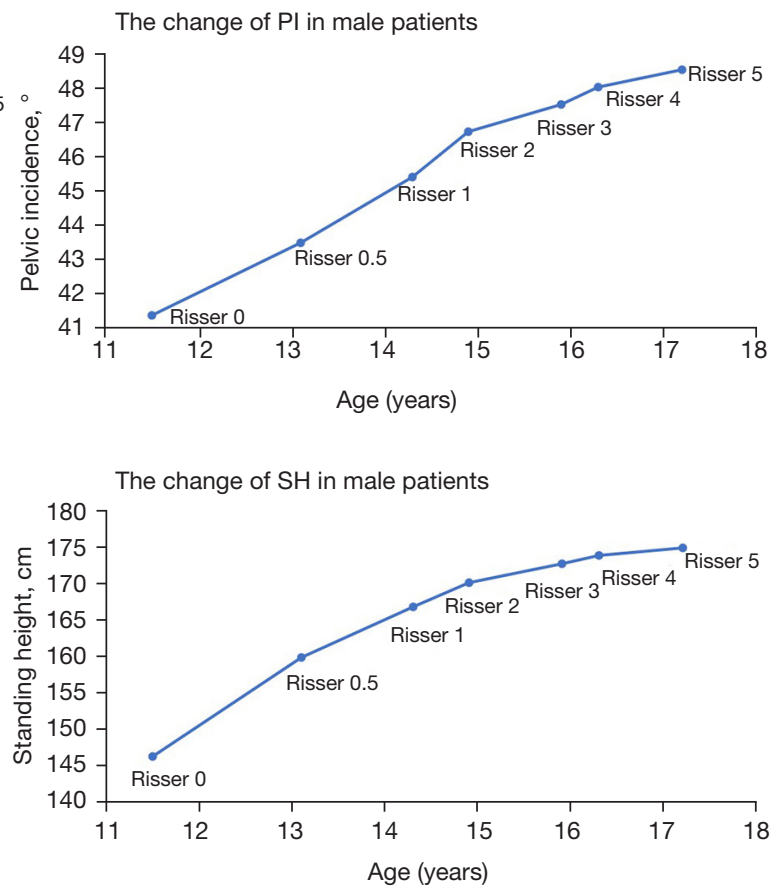

Figure 2 Changes of PI and SH in male and female patients. PI, pelvic incidence; SH, standing height.

increasing in Risser stages 3 and 4. The PHV occurred during Risser $0.5(6.83 \mathrm{~cm} /$ year for females, $7.32 \mathrm{~cm} /$ year for males).

The correlations between $\Delta \mathrm{PI}$ and the change in pelvic morphology are shown in Table 4. A significant strong correlation was found between $\triangle \mathrm{FH}-\mathrm{S}$ and $\triangle \mathrm{PI}$ in both female and male patients (female: $\mathrm{R}=0.601, \mathrm{P}<0.001$; male: $\mathrm{R}=0.508, \mathrm{P}<0.001)$. Significant moderate correlations were found between $\Delta \mathrm{SH}$ and $\Delta \mathrm{PI}$ (female: $\mathrm{R}=0.431, \mathrm{P}<0.001$; male: $\mathrm{R}=0.376, \mathrm{P}<0.001$ ), $\Delta \mathrm{PW}$ and $\Delta \mathrm{PI}$ (female: $\mathrm{R}=0.404$,
$\mathrm{P}<0.001$; male: $\mathrm{R}=0.397, \mathrm{P}<0.001)$ in both sexes. $\Delta \mathrm{PI}$ also correlated with $\Delta \mathrm{PH}, \Delta \mathrm{SW}$, and $\Delta \mathrm{S}-\mathrm{C}$ length (all $\mathrm{P}<0.05$ ). $\Delta \mathrm{PI}$ was not correlated with $\Delta \mathrm{S}-\mathrm{C}$ distance in female patients, and $\Delta \mathrm{PI}$ was not correlated with $\Delta \mathrm{S}-\mathrm{C}$ ratio in all patients.

\section{Discussion}

In recent years, sagittal spinal alignment has become a topic of great interest. The human pelvis, which articulates 
Table 2 Parameters and the growing velocity at different Risser stages in females

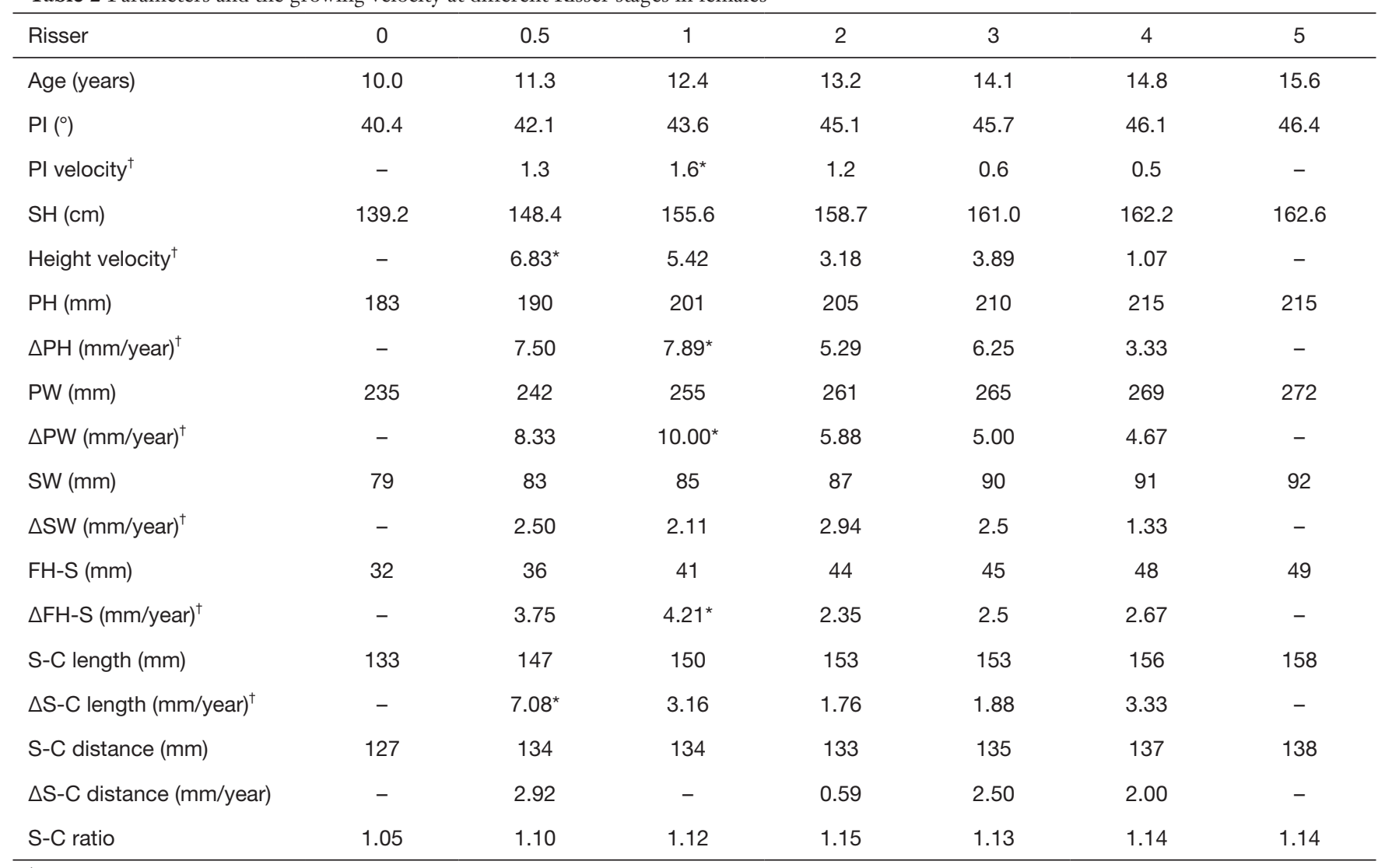

${ }^{\dagger}$, pairwise comparisons between all Risser stages showed statistically significant differences $(\mathrm{P}<0.05)$; ${ }^{*}$, statistical peak growth velocity of parameters. PI, pelvic incidence; $\mathrm{SH}$, standing height; $\mathrm{PH}$, pelvic height; $\mathrm{PW}$, pelvic width; SW, sacral width; FH-S, femoral head-sacrum; $\mathrm{S}-\mathrm{C}$, sacrum-coccyx.

with the spine and lower extremities, is very important in developing verticality. PI is a morphological parameter that reflects the relation between the sacrum and both iliac wings. As the sacral and pelvic morphology develop and change with age, the PI increases during skeletal growth $(10,17)$. Similar to previous conclusions, we also found increasing PI with age during adolescence. In addition, we also found that the peak PI velocity occurred during Risser stage 1 and that the change in PI correlated with increased $\mathrm{PW}$ as well as SW, S-C length, and FH-S distance.

In previous studies, Mangione et al. (17) reported that the PI stabilizes around the age of 10 years, but our data showed that the PI is still increasing after that age, and the increase continues to approximately age 17 . Schlösser et al. (10) reported a $0.6 \%$ year increase in the PI, remaining stable after skeletal maturity. Our results also showed a consistent increase during Risser $0.5-2$, with an average of $1.2-1.8 \%$ year. According to our correlation data, PI showed a significant correlation with pelvic and sacral morphology, indicating that the PI would change with the growth of the pelvis.

Our results revealed that the peak PI velocity occurred at Risser 1 in both females and males, which was later than the PHV (Risser 0 and closed triradiate cartilage) both in this study and a previous study (15).

This is the first study to provide data on the peak PI velocity. Völgyi et al. (18) reported the peak growth velocity of the PW in pubertal girls, demonstrating that the width of the greater pelvis reached the peak growth velocity about 2 months later than the PHV, indicating that the growth of the PW was a little behind the growth of the spine. Our study also showed a significant correlation between PI and PW in all subgroups. Therefore, the increase in the PI should be behind the PHV (represented as Risser 0 with closed triradiate cartilage), and thus the results of Völgyi et al.'s study also supported our conclusion that the PI 
Table 3 Parameters and the growing velocity at different Risser stages in males

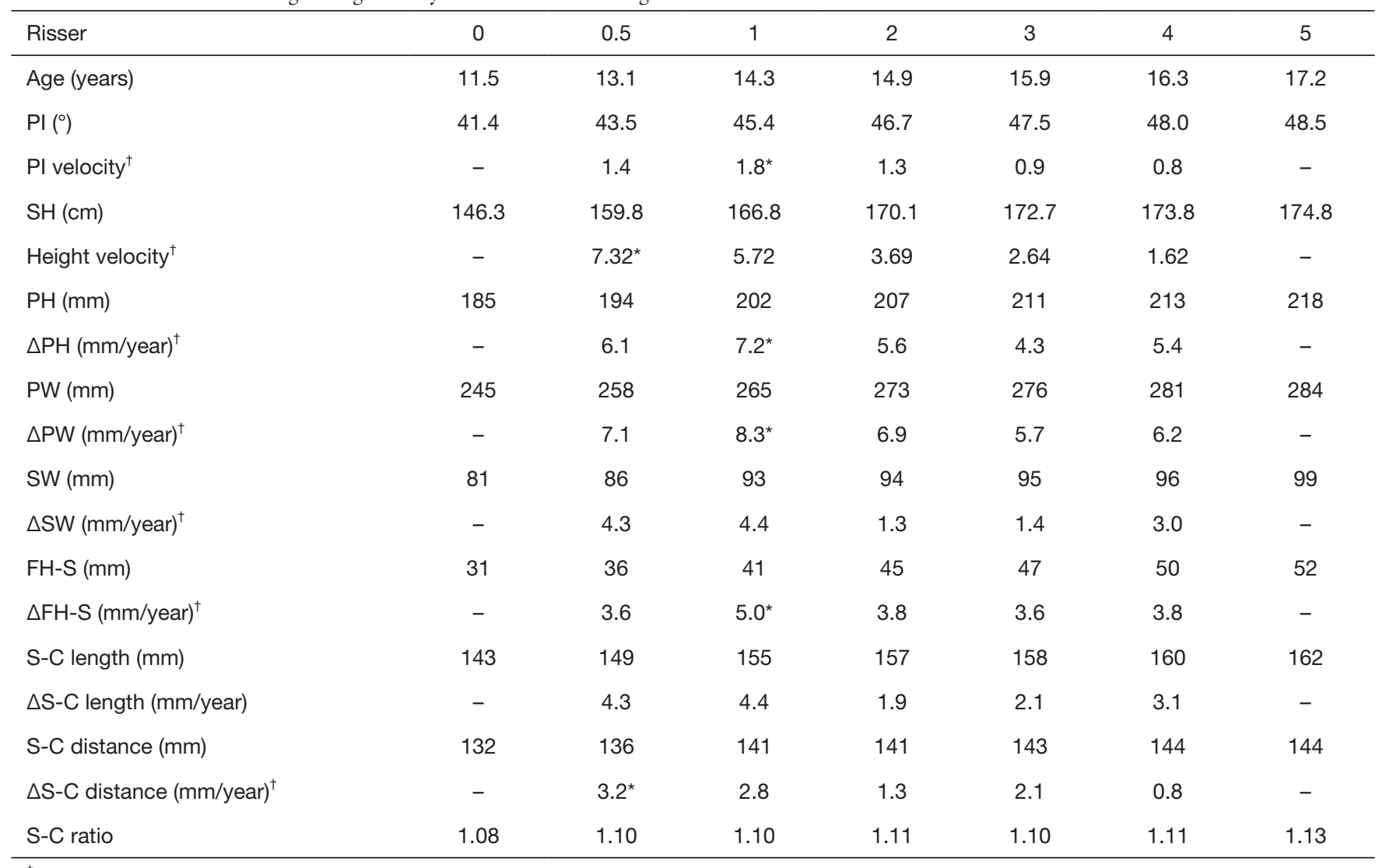

${ }^{\dagger}$, pairwise comparisons between all Risser stages showed statistically significant differences $(\mathrm{P}<0.05)$; ${ }^{*}$, statistical peak growth velocity of parameters. PI, pelvic incidence; $\mathrm{SH}$, standing height; $\mathrm{PH}$, pelvic height; PW, pelvic width; SW, sacral width; FH-S, femoral head-sacrum; S-C, sacrum-coccyx.

Table 4 Pearson correlation between $\Delta \mathrm{PI}$ and $\Delta$ Parameters in females and males

\begin{tabular}{lccccc}
\hline & \multicolumn{3}{c}{ Female } & & Male \\
\cline { 2 - 6 } & $\mathrm{R}$ & $\mathrm{P}$ & $\mathrm{R}$ & $\mathrm{P}$ \\
\hline$\Delta \mathrm{SH}$ & 0.431 & $<0.001$ & 0.376 & $<0.001$ \\
$\Delta \mathrm{PH}$ & 0.192 & 0.015 & 0.287 & $<0.001$ \\
$\Delta \mathrm{PW}$ & 0.404 & $<0.001$ & 0.397 & 0.295 & $<0.001$ \\
$\Delta \mathrm{SW}$ & 0.218 & 0.003 & 0.508 & $<0.001$ \\
$\Delta \mathrm{FH}-\mathrm{S}$ & 0.601 & $<0.001$ & 0.282 & 0.001 \\
$\Delta \mathrm{S}-\mathrm{C}$ length & 0.335 & $<0.001$ & 0.193 & 0.042 \\
$\Delta \mathrm{S}-\mathrm{C}$ distance & 0.078 & 0.214 & 0.031 & 0.672 \\
$\Delta \mathrm{S}-\mathrm{C}$ ratio & 0.056 & 0.472 & &
\end{tabular}

$\mathrm{PI}$, pelvic incidence; SH, standing height; PH, pelvic height; PW, pelvic width; SW, sacral width; FH-S, femoral head-sacrum; S-C, sacrum-coccyx. 
reaches the peak growth velocity in Risser 1 (18).

The existence of a distal-to-proximal growth gradient in adolescents has been reported: the peak pubertal growth is a combination of three micro-peaks: lower limb growth peaks first, followed by the peak trunk growth, and finally, the peak thoracic growth. This growth gradient may show deviations when we use the height growth velocity. Mao et al. (19) confirmed that the spinal growth velocity exerted a more direct influence over changes in curve progress as compared with the PHV in girls with idiopathic scoliosis. It could be speculated that the PHV should precede the peak spinal growth, suggesting that the result of delaying the peak PI velocity is understandable.

This study found that the change in PW showed a moderate correlation with the change in the PI, which was stronger than that between the change in PH and PI. This may be due to the measurement protocol of $\mathrm{PH}$ on coronal $\mathrm{X}$-ray images. $\mathrm{PH}$ is only a projection because the anteroposterior rotation of the pelvis in the sagittal plane may influence the measurement result. During adolescence, a consistent retroversion of the pelvis, represented as increased PT, has been extensively documented, diminishing $\mathrm{PH}$ measurement accuracy on coronal X-rays. We introduced a new parameter, $\triangle \mathrm{FH}-\mathrm{S}$, the horizontal distance between the center of the bicoxo-femoral axis and the posterior superior corner of the S1, which shows the thickness of the pelvis.

Similarly, the PI also reflects the thickness of the pelvis, which is also consistent with the strong correlation between $\Delta \mathrm{FH}-\mathrm{S}$ and $\Delta \mathrm{PI}$ in the results of our study. Therefore, we used another parameter, S-C length, to evaluate the vertical growth of the sacrum. Our results revealed a significant correlation between $\Delta \mathrm{S}-\mathrm{C}$ length and $\Delta \mathrm{PI}$, suggesting that the PI would change in accordance with pelvic or sacral morphology. These radiographic parameters, measured on two-dimensional $\mathrm{X}$-ray images, reflect the threedimensional morphological shape of the pelvis and can be used in the clinical setting to assess pelvic growth, as well as quantitative assessments for further clinical research.

By definition, the PI should be stable geometrically after skeletal maturity with a fixed sacroiliac joint. Therefore, the PI may change with an unstable sacroiliac joint. The growing pelvis and sacrum (increased width, height, and thickness) would alter the orientation of the sacroiliac joint, leading to increased PI during adolescence. Bao et al. (12) speculated that the PI increases with age because of motion at the sacroiliac joint caused by lumbosacral stress in adulthood. Place et al. (13) supposed that the PI changed when the pelvic position varied in healthy asymptomatic individuals during adulthood, probably because of potential functional motion at the sacroiliac joint. The changes in the PI that occur during adolescence may be due to the rapid growth of the pelvis during this time, where the anterior-posterior growth rate of the pelvis is greater than the longitudinal growth rate, increasing the thickness of the pelvis. In addition, we speculate that similar to the increase in the PI that occurs in the elderly during degeneration; adolescents undergo potential changes at the sacroiliac joint due to changes in body weight and peak skeletal development.

The PI is the foundation on which the spine is built, influencing the whole sagittal alignment of the spine (20). A higher PI appears to be a higher risk of spondylolisthesis and PJK $(5,21)$. In patients with AIS, the peak PI velocity is at Risser 1, and the PI is still increasing at Risser 5, so PIgrowth is associated with increased $\mathrm{SH}$ and the changing pelvic morphology during skeletal growth in adolescence. Our results suggested that the PI should be considered when evaluating the coronal plane's scoliosis in clinical practice. If the patient has a large PI, especially at the peak of skeletal growth during adolescence, the patient could be at risk of related spinal diseases.

There are several limitations to this study. First, the inclusion of the patients is the major limitation of this retrospective study. Many patients cease attending follow-up visits after discontinuation of brace treatment, so the sample size was not very large, and we cannot know the changes in the PI after adolescence. Future prospective studies can be designed to validate our study. Second, AIS patients were enrolled in this study instead of a normal population due to the difficulty of obtaining regular follow-up for normal subjects. Although a previous study showed that the PI was found similar in AIS and normal adolescents (22), future studies also prompted to the comparison of PI among normal adolescents. Future studies should include a normal population to evaluate the peak PI velocity. Despite these limitations, we clearly revealed the peak PI velocity during adolescence and the relationship between increased PI and changing anatomical morphology of the pelvis.

In conclusion, the peak PI velocity in AIS was at Risser 1, and it was still increasing at Risser 5. Our results suggested that changes in the PI are associated with $\mathrm{SH}$ and the changing pelvic morphology during skeletal growth in adolescence.

\section{Acknowledgments}

Funding: None. 


\section{Footnote}

Conflicts of Interest: All authors have completed the ICMJE uniform disclosure form (available at https://dx.doi. org/10.21037/qims-21-391). The authors have no conflicts of interest to declare.

Ethical Statement: The authors are accountable for all aspects of the work in ensuring that questions related to the accuracy or integrity of any part of the work are appropriately investigated and resolved. The study was conducted in accordance with the Declaration of Helsinki (as revised in 2013). This retrospective radiographic study was approved by the Institutional Review Board of the Affiliated Drum Tower Hospital of Nanjing University Medical School (No. 2017053) and informed consent was given by each subject.

Open Access Statement: This is an Open Access article distributed in accordance with the Creative Commons Attribution-NonCommercial-NoDerivs 4.0 International License (CC BY-NC-ND 4.0), which permits the noncommercial replication and distribution of the article with the strict proviso that no changes or edits are made and the original work is properly cited (including links to both the formal publication through the relevant DOI and the license). See: https://creativecommons.org/licenses/by-nc-nd/4.0/.

\section{References}

1. Dubousset J. Three-dimensional analysis of the scoliotic deformity. In: Weinstein SL. editor. The pediatric spine: principles and practice. New York: Raven Press Ltd., 1994:479-96.

2. Duval-Beaupère G, Schmidt C, Cosson P. A Barycentremetric study of the sagittal shape of spine and pelvis: the conditions required for an economic standing position. Ann Biomed Eng 1992;20:451-62.

3. Min WK, Lee CH. Comparison and correlation of pelvic parameters between low-grade and high-grade spondylolisthesis. J Spinal Disord Tech 2014;27:162-5.

4. Endo K, Suzuki H, Tanaka H, Kang Y, Yamamoto K. Sagittal spinal alignment in patients with lumbar disc herniation. Eur Spine J 2010;19:435-8.

5. Kim YJ, Bridwell KH, Lenke LG, Glattes CR, Rhim S, Cheh G. Proximal junctional kyphosis in adult spinal deformity after segmental posterior spinal instrumentation and fusion: minimum five-year follow-up. Spine (Phila Pa
1976) 2008;33:2179-84.

6. Kikuchi K, Miyakoshi N, Abe E, Kobayashi T, Abe T, Kinoshita H, Kimura R, Shimada Y. Proximal junctional fracture and kyphosis after long spinopelvic corrective fixation for adult spinal deformity. J Orthop Sci 2021;26:343-7.

7. Menezes-Reis R, Garrido Salmon CE, Bonugli GP, Mazoroski D, Savarese LG, Herrero CFPS, Defino HLA, Nogueira-Barbosa MH. Association between spinal alignment and biochemical composition of lumbar intervertebral discs assessed by quantitative magnetic resonance imaging. Quant Imaging Med Surg 2021;11:2428-41.

8. Mac-Thiong JM, Labelle H, Charlebois M, Huot MP, de Guise JA. Sagittal plane analysis of the spine and pelvis in adolescent idiopathic scoliosis according to the coronal curve type. Spine (Phila Pa 1976) 2003;28:1404-9.

9. Mac-Thiong JM, Berthonnaud E, Dimar JR 2nd, Betz RR, Labelle H. Sagittal alignment of the spine and pelvis during growth. Spine (Phila Pa 1976) 2004;29:1642-7.

10. Schlösser TP, Janssen MM, Vrtovec T, Pernuš F, Oner FC, Viergever MA, Vincken KL, Castelein RM. Evolution of the ischio-iliac lordosis during natural growth and its relation with the pelvic incidence. Eur Spine J 2014;23:1433-41.

11. Schlösser TP, Vincken KL, Rogers K, Castelein RM, Shah SA. Natural sagittal spino-pelvic alignment in boys and girls before, at and after the adolescent growth spurt. Eur Spine J 2015;24:1158-67.

12. Bao H, Liabaud B, Varghese J, Lafage R, Diebo BG, Jalai C, Ramchandran S, Poorman G, Errico T, Zhu F, Protopsaltis T, Passias P, Buckland A, Schwab F, Lafage V. Lumbosacral stress and age may contribute to increased pelvic incidence: an analysis of 1625 adults. Eur Spine J 2018;27:482-8.

13. Place HM, Hayes AM, Huebner SB, Hayden AM, Israel H, Brechbuhler JL. Pelvic incidence: a fixed value or can you change it? Spine J 2017;17:1565-9.

14. Abola MV, Teplensky JR, Cooperman DR, Bauer JM, Liu RW. Pelvic Incidence Is Associated With Sacral Curvature, Sacroiliac Joint Angulation, and Sacral Ala Width. Spine (Phila Pa 1976) 2018;43:1529-35.

15. Nault ML, Parent S, Phan P, Roy-Beaudry M, Labelle H, Rivard M. A modified Risser grading system predicts the curve acceleration phase of female adolescent idiopathic scoliosis. J Bone Joint Surg Am 2010;92:1073-81.

16. Bao H, Liu Z, Yan P, Qiu Y, Zhu F. Disproportionate growth between the spine and pelvis in patients with 
thoracic adolescent scoliosis: a new look into the pattern's growth. Bone Joint J 2015;97-B:1668-74.

17. Mangione P, Gomez D, Senegas J. Study of the course of the incidence angle during growth. Eur Spine J 1997;6:163-7.

18. Völgyi E, Tylavsky FA, Xu L, Lu J, Wang Q, Alén M, Cheng S. Bone and body segment lengthening and widening: a 7-year follow-up study in pubertal girls. Bone 2010;47:773-82.

19. Mao SH, Li HB, Jiang J, Sun X, Cheng JC, Qiu Y. An updated analysis of pubertal linear growth characteristics and age at menarche in ethnic Chinese. Am J Hum Biol 2011;23:132-7.

20. Roussouly P, Gollogly S, Noseda O, Berthonnaud E, Dimnet J. The vertical projection of the sum of the

Cite this article as: Zhang Y, Shu S, Gu Q, Mandelli F, Zhang T, Jing W, Qiu Y, Zhu Z, Bao H. Radiographic study of peak velocity of pelvic incidence in adolescent idiopathic scoliosis. Quant Imaging Med Surg 2022;12(2):1130-1138. doi: 10.21037/ qims-21-391 ground reactive forces of a standing patient is not the same as the C7 plumb line: a radiographic study of the sagittal alignment of 153 asymptomatic volunteers. Spine (Phila Pa 1976) 2006;31:E320-5.

21. Labelle H, Roussouly P, Berthonnaud E, Transfeldt E, O'Brien M, Chopin D, Hresko T, Dimnet J. Spondylolisthesis, pelvic incidence, and spinopelvic balance: a correlation study. Spine (Phila Pa 1976) 2004;29:2049-54.

22. Yong Q, Zhen L, Zezhang Z, Bangping Q, Feng Z, Tao W, Jun J, Xu S, Xusheng Q, Weiwei M, Weijun W. Comparison of sagittal spinopelvic alignment in Chinese adolescents with and without idiopathic thoracic scoliosis. Spine (Phila Pa 1976) 2012;37:E714-20. 